Original Article

\title{
Frequency of Post-Operative Cerebrospinal Fluid (CSF) Leak in Retromastoid Surgery for Vestibular Schwannoma: A Three-Year Experience of a Tertiary Care Hospital
}

\author{
Sohail Amir, Ayaz Ahmad, Atif Amman, Muhammad Ali Numan, Shahid Ayub \\ Department of Neurosurgery, Hayatabad Medical Complex, Peshawar - Pakistan
}

\begin{abstract}
Objective: Descriptive study was aimed is to find out the frequency of CSF leak in retro mastoid surgery for Vestibular Schwannoma.

Material and Methods: From 2017 to 2020, 63 patients underwent microsurgical excision of Vestibular Schwannoma with retro sigmoidal approach in the Department of Neurosurgery, Hayatabad Medical Complex, Peshawar. All patients of either sex underwent retro mastoid approach for Vestibular Schwannoma surgery, having complete dural closure per operatively were included in this study. Data was collected which included symptoms, clinical assessment, radiological findings, per-operative and postoperative findings. Patients were monitored for 30 days after surgery and checked for any CSF leaks.

Results: There were 36 male and 27 female patients. In our study, the postoperative CSF leak was present in $9(14 \%)$ of cases. There was no significant difference ( $p$-value 0.097) whether the dura was closed with graft and without graft. Insignificant differences existed in CSF leak vs. different age groups ( $p$-value 0.964) and gender (p-value: 0.917).

Conclusion: Our study found that after retro sigmoid approach for vestibular Schwannoma surgery, the frequency of CSF leak was $14 \%$, which gives us insight into our complication rate and allows us to change our surgical procedure technique, such as using fibrin glue or less frequently artificial dura, to reduce this rate.
\end{abstract}

Keywords: Cerebrospinal Fluid (CSF) Leak, Vestibular Schwannoma.

Corresponding Author: Sohail Amir

Department of Neurosurgery

Hayatabad Medical Complex, MTI - Peshawar

Email: dr.sohailamir@gmail.com

Date of Submission: 04-07-2021

Date of Revision: 30-08-2021

Date of Acceptance: 18-09-2021

Date of Online Publishing: 30-09-2021

Date of Print: 30-09-2021

DOI: $10.36552 /$ pjns.v25i3.574

\section{INTRODUCTION}

Vestibular Schwannoma (VS) is the most common Cerebellopontine angle (CPA) tumor, which accounts for 80 - 95 percent of all CPA tumors. ${ }^{1}$ They are slow to grow and arise from the junction between oligodendrocytes and Schwann cells (Obersteiner Redlich Zone). ${ }^{2}$ The inferior and superior vestibular nerves, peripheral parts, as well as the cochlear branch of the eighth cranial 
nerve, are the sites of origin of these tumors. These are uncommon, accounting for about $10 \%$ of primary intracranial tumors, $85 \%$ of Cerebellopontine angle tumors, and $90 \%$ of Schwannomas of the brain. ${ }^{3-4}$

Suboccipital, Trans labyrinthine, and middle fossa are three surgical approaches to an acoustic neuroma. ${ }^{5}$ The most frequent technique is the suboccipital retro sigmoid approach, which involves doing a craniectomy behind the ear in the occipital bone. This method may be utilized for any size tumor, but notably big ones, as long as facial nerve function and useful hearing are preserved. ${ }^{6}$.

Following many complex cranial procedures, post-operative CSF leakage can be hazardous. Especially with regards to the infratentorial field, where a watertight dural reconstruction is not always possible and pulsating waves of CSF are strongest. ${ }^{7}$ CSF leaks are a neurosurgeon's worst nightmare, resulting in longer hospital stays, risk of infections/meningitis, pain, and, higher costs. As a result, everything must be done to prevent CSF leaks after surgery. ${ }^{8-9}$

In literature, the occurrence of CSF leak after Vestibular Schwannoma surgeries varies from 2 to $30 \% .^{10}$ In the majority of studies; it is reported between $15-20 \% .^{11}$ The study was focused to find out the frequency of CSF leak in retro mastoid surgery for Vestibular Schwannoma.

\section{MATERIAL AND METHODS}

\section{Study Setting}

A descriptive study was conducted on patients who underwent microsurgical resection of Vestibular Schwannoma (VS) employing the retro sigmoidal approach. The study was conducted for three years at the Department of Neurosurgery, Hayatabad Medical Complex, Peshawar.

\section{Inclusion Criteria}

All patients of either sex undergoing retro mastoid approach for Vestibular Schwannoma surgery, having complete dural closure were included in this study.

\section{Exclusion Criteria}

Patients who had a prior history of surgery, incomplete dural closure per operatively, a combination supra and infratentorial method, or who had neurofibromatosis type II were eluded from the analysis.

\section{Data Collection}

After taking permission from the hospital ethical board review committee, all those Patients will be assessed further through a detailed history, which will include personal information such as name, age, sex, symptoms, clinical assessment, peroperative and post-operative findings. The trainee doctor recorded all the findings and examinations in a pre-designed Performa.

\section{Clinical Management}

Patients were monitored for 30 days after surgery via contact and will be checked for any CSF leaks by an expert neurosurgeon. The minimal followup was 6 months and all surgeries were performed in park bench position by a senior Neurosurgeon who has more than 20 years of experience in this field.

The dura was closed by vicryl 4/0 spongeston or surgical was placed in all cases and in some cases where dura was thin, a muscle patch was used.

\section{Data Analysis}

Data were analyzed using SPSS 25.0 version. A chi-square test was applied to see the significant differences between different stratified groups. A $\mathrm{p}$-value less than 0.050 were considered significant. 


\section{RESULTS}

\section{Age Distribution}

The age ranged from 20 to 60 years. 05 (8\%) patients were in the age group of 20 to 30 years followed by 09 (14\%) subjects of $30-40$ years, 26 $(41 \%)$ in the age range $41-50$ years, and 10 (15\%) were in the age group of $51-60$ years (Table 1).

Table 1: Age Distribution $(n=63)$.

\begin{tabular}{ccc} 
Age & Frequency & Percentage \\
$20-30$ years & 05 & $7.9 \%$ \\
$30-40$ years & 09 & $14.2 \%$ \\
$41-50$ years & 26 & $41.2 \%$ \\
$51-60$ years & 10 & $15.8 \%$ \\
Total & 63 & $100 \%$ \\
\hline
\end{tabular}

\section{Gender Distribution}

A total of 63 patients were included. There were 36 males and 27 females in a 1:1 ratio.

\section{CSF Leak Stratification (Gender, Age, \& Dural Repair)}

In our study, the postoperative CSF leak was present in $9(14 \%)$ of cases. There is no significant difference ( $p$-value 0.097) whether the dura was closed with graft and without graft. The stratification of CSF leak with age, gender, and dural repair has shown in Tables 2 - 4 . Insignificant differences existed in CSF leak vs. different age groups ( $p$-value 0.964) and gender (p-value: 0.917).

Table 2: CSF Leak Stratification by Age Groups $(n=63)$.

\begin{tabular}{|c|c|c|c|c|c|c|c|c|}
\hline $\begin{array}{l}\text { Postoperative } \\
\text { CSF Leak }\end{array}$ & $\begin{array}{c}20-30 \\
\text { Years } \\
\text { Group } 1\end{array}$ & $\begin{array}{c}31-40 \\
\text { Years } \\
\text { Group } 2\end{array}$ & $\begin{array}{c}41-50 \\
\text { Years } \\
\text { Group } 3\end{array}$ & $\begin{array}{c}51-60 \\
\text { Years } \\
\text { Group } 4\end{array}$ & $\begin{array}{c}>60 \text { Years } \\
\text { Group } 5\end{array}$ & Total & $\begin{array}{c}\text { Chi- } \\
\text { Square* }\end{array}$ & p-value \\
\hline Yes & 0 & 1 & 4 & 2 & 2 & 9 & \multirow{3}{*}{0.2871} & \multirow{3}{*}{$\begin{array}{c}0.964 \\
\text { insignificant }\end{array}$} \\
\hline No & 5 & 8 & 22 & 11 & 8 & 54 & & \\
\hline Total & 5 & 9 & 26 & 13 & 10 & 63 & & \\
\hline
\end{tabular}

${ }^{*}$ chi-square was applied in groups $2-5$

Table 3: Sex and CSF Leak Stratification $(n=63)$.

\begin{tabular}{|lrrrrc|}
$\begin{array}{l}\text { Post- } \\
\text { operative } \\
\text { CSF Leak }\end{array}$ & Male & Female & Total & $\begin{array}{c}\text { Chi- } \\
\text { Square }\end{array}$ & p-value \\
Yes & 5 & 4 & 9 & & 0.9172 \\
No & 31 & 23 & 54 & 0.0108 & insignificant \\
Total & 36 & 27 & 63 & & \\
\hline
\end{tabular}

Table 4: CSF leak Stratification with Dural Repair $(n=$ 63).

\begin{tabular}{|lccccc|}
$\begin{array}{l}\text { Post- } \\
\text { operative } \\
\text { CSF leak }\end{array}$ & $\begin{array}{c}\text { Dural } \\
\text { Repair } \\
\text { Without } \\
\text { Graft }\end{array}$ & $\begin{array}{c}\text { Dural } \\
\text { Repair } \\
\text { with } \\
\text { Graft }\end{array}$ & $\begin{array}{c}\text { Total } \\
\text { Chi- } \\
\text { Square }\end{array}$ & p-value \\
Yes & 4 & 5 & 9 & & \\
No & 39 & 15 & 54 & 2.7471 & $\begin{array}{c}0.097 \\
\text { insignificant }\end{array}$ \\
\hline
\end{tabular}

\section{DISCUSSION}

Microsurgical procedures, intraoperative neurophysiological monitoring, and neuroanesthesia, as well as advanced neurointensive care, have made operative measures of vestibular Schwannoma effective, with low mortality and morbidity. However, complications may occur, the most common of which is CSF leak. ${ }^{12}$

CSF leaks were found to be 14 percent of the time in our report. It has been estimated to be between 2 and $30 \%$ in the literature. Seven patients (8.6\%) developed a fistula for the CSF, as reported by Arlt et al. Three patients (3.7\%) underwent surgery due to a persistent CSF fistula, while four patients (4.9\%) experienced 
spontaneous closure while using a lumbar drain. ${ }^{10}$ According to Sathaporntheera and Saetia's study, CSF leakage occurred in 40 of 286 patients (14\%), which is consistent with our findings. ${ }^{13}$ Jacoeb et al, found a 13 percent incidence in similar research. Huang et al, studied 430 subjects and concluded the frequency of CSF leak is $20 \% .{ }^{14} \mathrm{~A}$ study conducted in 2017 by Akramulla et al, observed 132 patients operated for infratentorial surgery and concluded $9 \%$ of CSF leaks which also corresponds to our study. ${ }^{15}$

To avoid CSF leaking, water tight Dural closure was advised in the early days of neurosurgery. Primary dural closure (primary reapproximation and suturing of the dural edges) provides the strongest seal without the use of autologous or artificial dural replacements. Primary Dural closure is not always achievable due to electrocautery of the dura mater and dehydration of the exposed dura. In our study 43 (68\%) of patients received dural watertight repair without graft. In 20 patients (31\%) muscle/fat grafts were used. In both groups, the frequency of CSF leak is $6 \%$ and $7 \%$, respectively. It concluded that there is no significant difference between the two groups. A similar study was done by Arlt $^{1}$ et al. on 81 patients that received microsurgical tumor resection using a suboccipital, retro sigmoidal technique between January 2003 and December 2009 and found that there was no substantial difference in the frequency of CSF leaks between different dural repair techniques. ${ }^{10}$

We found disordered vestibular compensation in $15 \%$ of cases, permanent trigeminal nerve dysfunction in $2 \%$ of cases, facial nerve damage in $15 \%$ of cases, transient lower cranial nerves (IX $\mathrm{XI})$ deficit in $13 \%$ of cases, headache in $9 \%$ of cases, and intracerebral hemorrhage in $5 \%$ of cases in the current study. Betka et al, showed a similar outcome ${ }^{9}$. A study conducted by Jeffrey et al, in 2001 in Canada included 624 patients and observed an overall incidence of $11 \%$ CSF leak which again correlates to over results. ${ }^{16}$

\section{CONCLUSION}

Our research found that after retro sigmoid approach for vestibular Schwannoma surgery, the frequency of CSF leak was $14 \%$, which gives us insight into our complication rate and allows us to change our surgical procedure technique, such as using fibrin glue or artificial dura, to reduce this rate.

\section{RECOMMENDATIONS}

CSF leakage ranks significantly in the complication chart list for retrosigmoidal approaches and must be avoided with the employment of meticulous surgical techniques and great care at all steps during the procedure. Use of fibrin glue or artificial dural graft practices maybe used to reduce the incidence. We need larger and multicenter studies to affirm these facts.

\section{REFERENCES}

1. Jackler PK, Pfister MHF. Acoustic Neuroma (Vestigular Schwannoma). Neurotology, 2005; (August): 727-82.

2. Myrseth $E$, Pedersen $P H$, Møller P, Lund-Johansen $M$. Treatment of vestibular schwannomas. Why, when, and how? Acta Neurochir (Wien), 2007; 149 (7): 647-60.

3. Propp JM, McCarthy BJ, Davis FG, Preston-Martin S. Descriptive epidemiology of vestibular schwannomas. Neuro Oncol. 2006; 8 (1): 1-11.

4. Reznitsky M, Petersen MMBS, West N, Stangerup $\mathrm{SE}$, Cayé-Thomasen P. Epidemiology of vestibular schwannomas - prospective 40-year data from an unselected national cohort. Clin Epidemiol. 2019; 11: 981-6.

5. Silk PS, Lane Jl, Driscoll CL. Surgical approaches to vestibular schwannomas: What the radiologist needs to know. Radiographics, 2009; 29 (7): 195570.

6. Chamoun R, MacDonald J, Shelton C, Couldwell WT. Surgical approaches for resection of vestibular schwannomas: Translabyrinthine, retrosigmoid, and middle fossa approaches. Neurosurg Focus, 
2012; 33 (3): 3-7.

7. hoffman1994.pdf.

8. Stieglitz LH, Wrede $\mathrm{KH}$, Gharabaghi A, Gerganov VM, Samii A, Samii $M$, et al. Factors affecting postoperative cerebrospinal fluid leaks after retrosigmoidal craniotomy for vestibular schwannomas: Clinical article. J Neurosurg. 2009; 111 (4): 874-83.

9. Betka J, Zvěřina E, Balogová Z, Profant O, Skřivan J, Kraus J, et al. Complications of microsurgery of vestibular schwannoma. Biomed Res Int. 2014: 2014.

10. Arlt F, Trantakis C, Krupp W, Renner C, Winkler D, Strauss $G$, et al. Cerebrospinal fluid leak after microsurgical surgery in vestibular schwannomas via retrosigmoidal craniotomy. Neurol Res. 2011; 33 (9): 947-52.

11. Fishman AJ, Marrinan MS, Golfinos JG, Cohen NL, Roland JT. Prevention and Management of Cerebrospinal Fluid Leak Following Vestibular Schwannoma Surgery. Laryngoscope, 2004; 114 (3): 501-5.

12. Yamakami I, Uchino Y, Kobayashi E, Yamaura A, Oka N. Removal of large acoustic neurinomas (vestibular schwannomas) by the retrosigmoid approach with no mortality and minimal morbidity. J Neurol Neurosurg Psychiatry, 2004; 75 (3): 453-8.

13. Sathaporntheera $P$, Saetia K. Risk factors associated with CSF leakage and complications after retrosigmoid surgery. Interdiscip Neurosurg Adv Tech Case Manag [Internet], 2020; 22 (June): 100865. Available from: https://doi.org/10.1016/j.inat.2020.100865

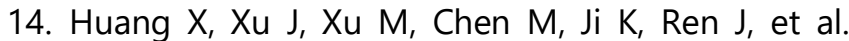
Functional outcome and complications after the microsurgical removal of giant vestibular schwannomas via the retrosigmoid approach: A retrospective review of 16-year experience in a single hospital. BMC Neurol. 2017; 17 (1): 1-9.

15. Ullah A, Ali M, Siddiq M. Frequency of PostOperative Cerebrospinal Fluid Leak after Infratentorial Surgery, 2017; 21 (1).

16. Brennan JW, Rowed DW, Nedzelski JM, Chen JM. Cerebrospinal fluid leak after acoustic neuroma surgery: Influence of tumor size and surgical approach on incidence and response to treatment. J Neurosurg. 2001; 94 (2): 217-23.

\section{Additional Information}

Disclosures: Authors report no conflict of interest.

Ethical Review Board Approval: The study was conformed to the ethical review board requirements.

Human Subjects: Consent was obtained by all patients/participants in this study.

\section{Conflicts of Interest:}

In compliance with the ICMJE uniform disclosure form, all authors declare the following:

Financial Relationships: All authors have declared that they have no financial relationships at present or within the previous three years with any organizations that might have an interest in the submitted work.

Other Relationships: All authors have declared that there are no other relationships or activities that could appear to have influenced the submitted work. 


\section{AUTHORS CONTRIBUTIONS}

\begin{tabular}{|l|l|l|}
\hline Sr.\# & Author's Full Name & Intellectual Contribution to Paper in Terms of: \\
\hline 1. & Sohail Amir & Study design and methodology. \\
\hline 2. & Ayaz Ahmad & Paper writing, referencing, and data calculations. \\
\hline 3. & Atif Aman & Data collection and calculations. \\
\hline 4. & Muhammad Ali Noman & Analysis of data and interpretation of results etc. \\
\hline 5. & Shahid Ayub & Literature review and manuscript writing and quality insurer. \\
\hline
\end{tabular}

